\title{
Effects of in ovo Injection of Astragalus Polysaccharide on the Intestinal Development and Mucosal Immunity in Broiler Chickens
}

\author{
Shu-bao Yang ${ }^{1,2+}$, Yan-jun Qin ${ }^{2+}$, Xin $\mathrm{Ma}^{2}$, Wei-min Luan ${ }^{2}$, Peng Sun ${ }^{2}, \mathrm{An}-q i \mathrm{Ju}^{2}$, \\ Ao-yi Duan ${ }^{2}$, Ying-nan Zhang ${ }^{3,4 *}$ and Dong-hai Zhao ${ }^{\text {1* }}$ \\ ${ }^{1}$ Basic Medical College, Jilin Medical University, Jilin, China, ${ }^{2}$ College of Animal Science and Technology, Jilin Agricultural \\ University, Changchun, China, ${ }^{3}$ School of Public Health, Jilin Medical University, Jilin, China, ${ }^{4}$ College of Life Science, \\ Changchun Sci-Tech University, Changchun, China
}

\section{OPEN ACCESS}

Edited by:

Monika Pogány Simonová, Slovak Academy of Sciences, Slovakia

Reviewed by:

Bangyuan Wu,

China West Normal University, China

Servet Yalcin,

Ege University, Turkey

Djoni Prawira Rahardja,

Hasanuddin University, Indonesia

*Correspondence:

Ying-nan Zhang

zhangyingnan1983@163.com

Dong-hai Zhao

zdh1027@sina.com

†These authors have contributed equally to this work and share first

authorship

Specialty section:

This article was submitted to Animal Nutrition and Metabolism,

a section of the journal

Frontiers in Veterinary Science

Received: 09 July 2021 Accepted: 09 August 2021

Published: 30 August 2021

Citation:

Yang S-b, Qin Y-j, Ma X, Luan W-m,

Sun P, Ju A-q, Duan A-y, Zhang Y-n and Zhao D-h (2021) Effects of in ovo Injection of Astragalus Polysaccharide

on the Intestinal Development and Mucosal Immunity in Broiler Chickens.

Front. Vet. Sci. 8:738816.

doi: 10.3389/fvets.2021.738816
The purpose of this study was to examine the effects of in ovo injection of Astragalus polysaccharide (APS) on hatchability, body weight (BW), intestinal histomorphology, the number of $\operatorname{lgA}^{+}$cells and slgA content in intestine, and the expression of intestinal immune-related genes in broiler chickens. On day 18 of the incubation, a total of 960 live embryo eggs were weighed and randomly divided into 4 treatment groups: a control group and three APS groups. The eggs in the control group were injected with $0.5 \mathrm{~mL}$ physiological saline. The eggs in the APS groups were injected with 3 different amounts of APS in $0.5 \mathrm{~mL}$ physiological saline: $1 \mathrm{mg}\left(\mathrm{APS} \mathrm{L}_{\mathrm{L}}\right), 2 \mathrm{mg}\left(\mathrm{APS}_{\mathrm{M}}\right)$ and $4 \mathrm{mg}\left(\mathrm{APS}_{\mathrm{H}}\right)$. The solution was injected into the amnion of each egg. The results showed that in ovo injection of APS did not affect the hatchability but increased the body weight of the $14 d$ and 21 $d$ chickens, with a significant increase observed in the APS $_{M}$ group $(P<0.05)$. At most time points, the villus height $(\mathrm{VH})$ was increased $(P<0.05)$ and the crypt depth $(\mathrm{CD})$ was decreased $(P<0.05)$ in the small intestine of the broilers, with higher $\mathrm{VH} / \mathrm{CD}$ ratios in the $A P S_{L}$ and $A P S_{M}$ groups compared with the control group. The number of $\lg A^{+}$cells in the mucosa and the secretory immunoglobulin $A$ (slgA) levels in the intestinal washings were higher in the $\mathrm{APS}_{\mathrm{M}}$ and $\mathrm{APS}_{\mathrm{H}}$ groups than in the APS $\mathrm{L}_{\mathrm{L}}$ and control groups. The gene expression levels of interleukin (IL)-2, interleukin (IL)-4, interferon gamma (IFN- $\gamma$ ), and Toll-like receptor (TLR)-4 were significantly enhanced by APS stimulation at most time points $(P<0.05)$. These results indicated that in ovo injection of APS has the potential of promoting intestinal development and enhancing intestinal mucosal immunity of broiler chickens in the early stage after hatching.

Keywords: Astragalus polysaccharide, in ovo injection, intestinal development, intestinal mucosal immunity, broilers

\section{INTRODUCTION}

In comparison to mammals, the growth and development of the avian embryo and hatchling are dependent on the nutrients in the fertile eggs. Due to avian embryos' rapid growth and high metabolism, they have a great demand for energy and nutrients during late embryonic development, resulting in an imbalance between the consumption and retention of nutrients within 
the eggs (1). In recent years, in ovo feeding during incubation is regarded as a way to correct this imbalance by providing additional nutrients to meet the developmental needs of embryos and post-hatch chickens during fasting $(2,3)$.

Newly hatched chickens have limited maternal antibodies and immature immune and digestion systems, which make them susceptible to infections. Early research showed that intestinal mucosa is a vital tissue that maintains nutrition and immunity in the body $(4,5)$. Therefore, strengthening the intestinal immune function to improve resistance against external pathogens plays a key role in the survival and development of young chickens (6). Newly hatched chicks are restricted in their access to feed for $\sim 48-72 \mathrm{~h}$ in commercial poultry rearing. As studies indicated the fasting may lead to retardation in development of the gastrointestinal tract and even the entire body $(7,8)$. Studies have shown that in ovo injection of various biologics into the amnion, such as prebiotics and synbiotics, may rapidly promote small intestinal growth and development by establishing a healthy and balanced gastrointestinal tract (GIT) microbiome in the early stage of its formation $(9,10)$.

Astragalus is a kind of Chinese medicinal herb that has been used in oriental medicine for thousands of years. Astragalus polysaccharide (APS) is a type of water-soluble heteropolysaccharide with bioactive effects, which is extracted from the stems or dried roots of Astragalus. The components are complex and diverse, and polymeric carbohydrates are mainly linked by a-type glycosidic bonds between the monosaccharides (11). Astragalus polysaccharide (APS) is the main ingredient extracted from Astragalus, which has multiple biological activities, including immunomodulatory, anti-viral, anti-tumor, and anti-oxidant properties (12). Previous studies indicated that APS possesses the effect of promoting intestinal development and modulating intestinal mucosal immunity of chicks when taken orally or as a feed additive $(13,14)$. The modulatory effect of APS on intestinal mucosal immunity in broilers is considerably dependent on the interaction with various immunoglobulins (e.g., $\operatorname{IgA}, \operatorname{IgG}$ ) and cytokines (e.g., IL-2, IL-4, and IL-6) when foreign antigen is present in the body of the broilers (15-17). However, little is known about the effect of in ovo injection of APS on the intestinal development and intestinal mucosal immunity in broiler chicks.

Therefore, the aim of the present study was to evaluate the effect of in ovo injection with 3 different amounts of APS on the intestinal development and mucosal immunity in broilers by determinations of hatchability, body weight, intestinal histomorphology, the distribution and number of $\operatorname{IgA}^{+}$cells, sIgA levels, and the expression of intestinal immune-related genes. The information obtained in this study can therefore be useful for understanding effects of in ovo injection of APS on growth and immunity adjustment in poultry industry.

Abbreviations: APS, Astragalus polysaccharide; BW, body weight; AA+ broilers, Arbor Acres broilers; VH, villus height; $\mathrm{CD}$, depth of crypt; HE staining, hematoxylin-eosin staining; $\mathrm{DAB}$, diaminobenzidine.

\section{MATERIALS AND METHODS}

\section{Experimental Design and Egg Incubation}

This study was conducted following the Jilin Agriculture University Institutional Animal Care and Use Committee (JLAU08201409), and the experimental procedures were performed in compliance with the National Institutes of Health Guide for the Care and Use of Laboratory Animals (NIH Publications No. 8,023).

Fertilized Arbor Acres $(\mathrm{AA}+)$ broiler eggs were obtained from a broiler breeder farm (Runcheng Broiler Breeding Factory, Changchun, China). All eggs with a similar weight (60.27 \pm $0.15 \mathrm{~g}$ ) were incubated under standard conditions in a Hongtai incubator (Hongtai Incubation Equipment Factory, China). On days 12 and 18 of incubation, the eggs were candled and the unfertilized eggs and dead embryos were discarded. A total of 960 live embryo eggs were weighed and randomly allocated to 4 treatment groups (a control group and three APS groups), consisting of 3 replicates of 80 eggs each on day 18 of incubation. APS (net content 91.9\%) was purchased from Sihai Plant Extracts Co., Ltd. (Nantong, China). The control group was injected with $0.5 \mathrm{~mL}$ physiological saline, while the three experimental groups $\left(\mathrm{APS}_{\mathrm{L}}, \mathrm{APS}_{\mathrm{M}}\right.$, and $\mathrm{APS}_{\mathrm{H}}$ group) were injected with $0.5 \mathrm{~mL}$ of 3 different concentrations of APS solution (1,2, and $4 \mathrm{mg}$ APS in $0.5 \mathrm{~mL}$ physiological saline), respectively. The saline and APS solutions were injected into the amnion of each egg vertically from the top of the larger end of the eggshell to a depth of $2.49 \mathrm{~cm}$ using a 22-gauge needle. A new needle was used for each injection. After in ovo injection, the holes were sealed with sterile paraffin and the eggs were returned to the incubator. Each tray of eggs of each treatment group remained outside the incubator for $\sim 15$ min during the injection period.

\section{Animal Treatment and Sample Collection/Data Collection}

On the day of hatching, the hatchability of the injected live embryonated eggs was calculated, and all male hatched chicks from one treatment were pooled and weighted. A total of 75 male chicks from each of the four experimental treatments with a similar weight close to the average body weight (BW) of their pooled group were selected and randomly assigned into 3

TABLE 1 | Specific primers for $\beta$-actin, IL-2, IL-6, IFN- $\gamma$, and TLR-4.

\begin{tabular}{lllc}
\hline Gene & Primer & Sequence & Amplicon size (bp) \\
\hline$\beta$-actin & Forward & TGATATTGCTGCGCTCGTTG & 143 \\
& Reverse & CTITCTGGCCCATACCAACC & \\
IL-2 & Forward & CAAGAGTCTTACGGGTCTAAATCAC & 100 \\
& Reverse & GTTGGTCAGTTCATGGAGAAATC & \\
IL-6 & Forward & CAAGGTGACGGAGGAGGAC & 254 \\
& Reverse & TGGCGAGGAGGGATTCT & 127 \\
IFN- $\gamma$ & Forward & GACAAGTCAAAGCCGCACA & 190 \\
& Reverse & TCAAGTCGTTCATCGGGAGC & \\
TLR-4 & Forward & CCACACACCTGCCTACATGAA &
\end{tabular}


replicates of 25 chicks each. A total of 12 cages were provided for the four treatments, with each replicate allocated to a cage. Chicks were reared up to $21 \mathrm{~d}$ of age and were offered water and a standard broiler diet ad libitum. On days 1, 7, 14, and 21 posthatch, five birds per replicate were weighed and euthanized by cervical dislocation, and the duodenum, jejunum, and ileum were separated. A hematoxylin and eosin (H\&E) staining method was used to observe changes in the intestinal morphological structure, and the distribution and quantity of $\operatorname{IgA}^{+}$cells in the intestinal mucosa were studied by immunohistochemical staining. The changes in sIgA content in jejunal washing were detected by an enzyme-linked immunosorbent assay (ELISA). Real-time PCR was used to detect the expression of IL-2, IL-6, IFN- $\gamma$, and TLR-4 mRNA in the ileum.

\section{Histomorphological Measurements}

Intestinal segments (duodenum, jejunum, and ileum) were fixed in $10 \%$ formalin, embedded in paraffin, then cut into $6-\mu \mathrm{m}$ thick sections (Typ RM 2235, Leica, Germany), and stained using a hematoxylin and eosin (H\&E) method. Five villi and crypts for 5 sections per sample in each chicken from each group were measured and analyzed using Image-Pro Plus 6.0 software (Media Cybernetics, USA). The villus height (VH) was measured from the top of the villus to the crypt mouth, the depth of the invagination between adjacent crypt mouths was measured and defined as crypt depth $(\mathrm{CD})$, and the ratio of $\mathrm{VH} / \mathrm{CD}$ was calculated.

\section{Analysis of Intestinal $\lg \mathrm{A}^{+}$Cells}

The segments of duodenum and jejunum embedded with paraffin wax were cut into $6-\mu \mathrm{m}$ thin sections with sledge microtome (Typ RM 2235, Leica, Germany), the paraffin was removed prior to staining with xylol, and then the sections were incubated with citrate-buffered solution $(\mathrm{pH} 6.0,0.01 \mathrm{M})$ at $95^{\circ} \mathrm{C}$ for $20 \mathrm{~min}$. The distribution and numbers of $\mathrm{IgA}^{+}$cells in the duodenum and jejunum were identified with an immunohistochemistry staining method described previously (14). The reactions were made visible with metal-enhanced diaminobenzidine (DAB). After staining, the sections were slightly counterstained with hematoxylin. The staining sections were observed under $100 \times$ amplification (Olympus CX41 microscope and the Pixera
pro600ES image acquisition unit, Pixera, USA) and measured using Image-pro plus 6.0 software (Media Cybernetics, USA). The IgA ${ }^{+}$cells of five views from each slice from five sections per group were counted, and the average numbers of $\mathrm{IgA}^{+}$ cells per view (over areas of $0.01 \mathrm{~mm}^{2}$ ) for each group were calculated.

\section{Detection of SIgA Content in Jejunum}

As described by Shan et al. (14), 5-cm sections of the jejunum were removed, infused with $0.5 \mathrm{~mL}$ PBS ( $\mathrm{pH} 7.4$, containing $0.1 \%$ BSA and aprotinin) and washed three times. The washings were collected and centrifuged at $10,950 \times \mathrm{g}$ at $4^{\circ} \mathrm{C}$ for $10 \mathrm{~min}$. The supernatants were collected to determine the sIgA levels in the jejunum mucosa using an ELISA according to the instructions of the Chicken sIgA Kit-BPE60021 (Lengton Bioscience Co., Ltd., Shanghai, China). Optical density was measured using a microplate reader (Sunrise-Basic, Switzerland) at $450 \mathrm{~nm}$.

\section{Real-Time Quantitative RT-PCR (qRT-PCR)}

The ileum samples were removed, and 20-30 mg aliquots were weighed. The total RNA of the ileum was extracted according to the instruction of the RNA simple Total RNA kit-DP431 (Tiangen Biotechnology Co., Ltd., Beijing, China) and reverse transcribed into cDNA using the PrimeScript TM Reagent Kit with gDNA Eraser (DRR047A) (Tiangen Biotechnology Co., Ltd., Beijing, China). The amplification and detection were conducted using the SYBR ${ }^{\circledR}$ Premix Ex TaqTM II Real-time RT-PCR (qRT-PCR) kit (Bao Bioengineering Co., Ltd., Dalian, China) in an Applied Biosystems 7500 FAST Real-Time PCR System. During the PCR, the samples were subjected to an initial denaturation phase at $95^{\circ} \mathrm{C}$ for $20 \mathrm{~s}$, followed by 40 cycles of denaturation at $95^{\circ} \mathrm{C}$ for $3 \mathrm{~s}$, and annealing and extension at $60^{\circ} \mathrm{C}$ for $30 \mathrm{~s}$. The gene expression of IL-2, IL-6, IFN$\gamma$, and TLR-4 was analyzed using $\beta$-actin as an endogenous control. The forward and reverse primer sequences are listed in Table 1. We obtained the relative gene expression level using the $2^{-\Delta \Delta C T}$ method. All PCR operations were performed in triplicate.

\section{Statistical Analysis}

Data were analyzed using SPSS 22.0 (SPSS Inc., Cary, NC, USA). One-way analysis of variance (ANOVA) with

TABLE 2 | Effect of in ovo injection of APS on hatchability and BW.

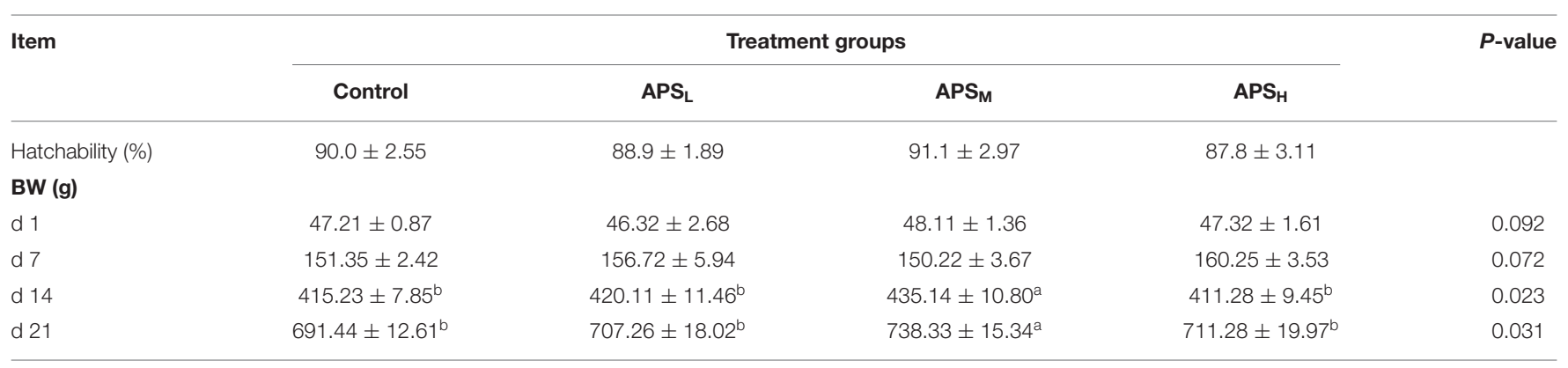

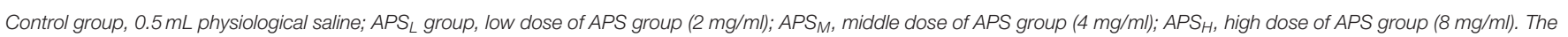
results are reported as the means \pm SEM.

${ }^{a, b}$ Means with different superscripts within the same column differ significantly $(P<0.05)$. 

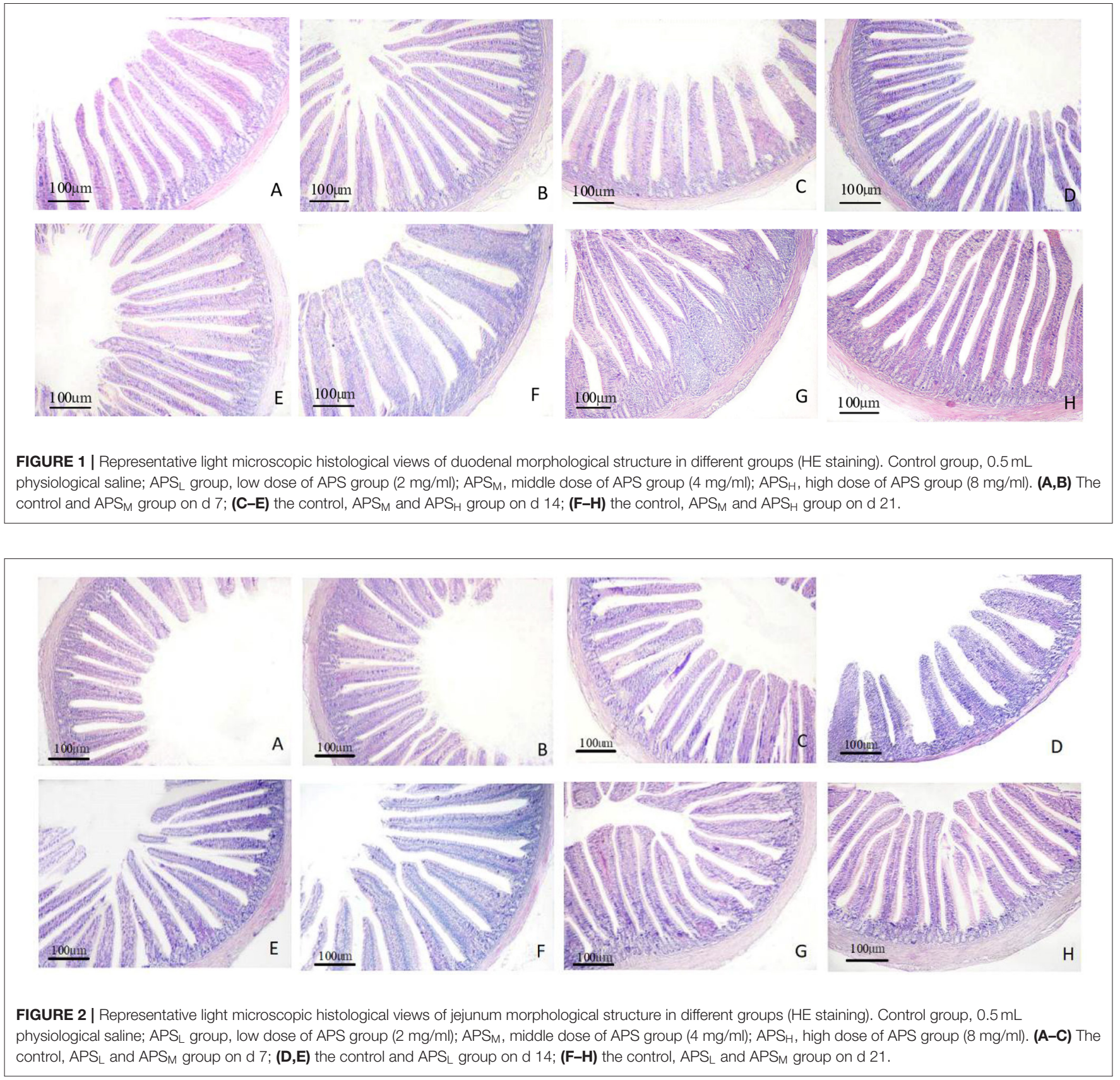

a Duncan post-hoc test was used for multiple comparisons among different groups. The overall data are expressed as the mean \pm SEM, and significant differences were considered at $P<0.05$.

\section{RESULTS}

\section{Hatchability and Post-hatch BW}

There were no significant differences in hatchability among the four groups $(P>0.05$, Table 2$)$. BW were not affected by in ovo treatment on days 1 and 7 post-hatch, and no significant differences were observed among the four groups $(P>0.05)$.
However, on d 14 and d 21, the BW in the $\mathrm{APS}_{\mathrm{M}}$ group was significantly higher than those in the other three groups $(P<$ 0.05 , Table 2).

\section{Intestinal Histomorphological Analyses}

The morphology changes in the duodenum, jejunum, and ileum are shown in Figures 1-3. Compared to the control group, the duodenal villi were in a closer and more orderly array on $\mathrm{d} 7$ and d 14. On d 21, the duodenal glands were better developed in the three APS groups (Figure 1). With increasing age, the jejunal villi in the three APS groups grew longer and their arrangement was closer than those in the control group (Figure 2). The villi of the 


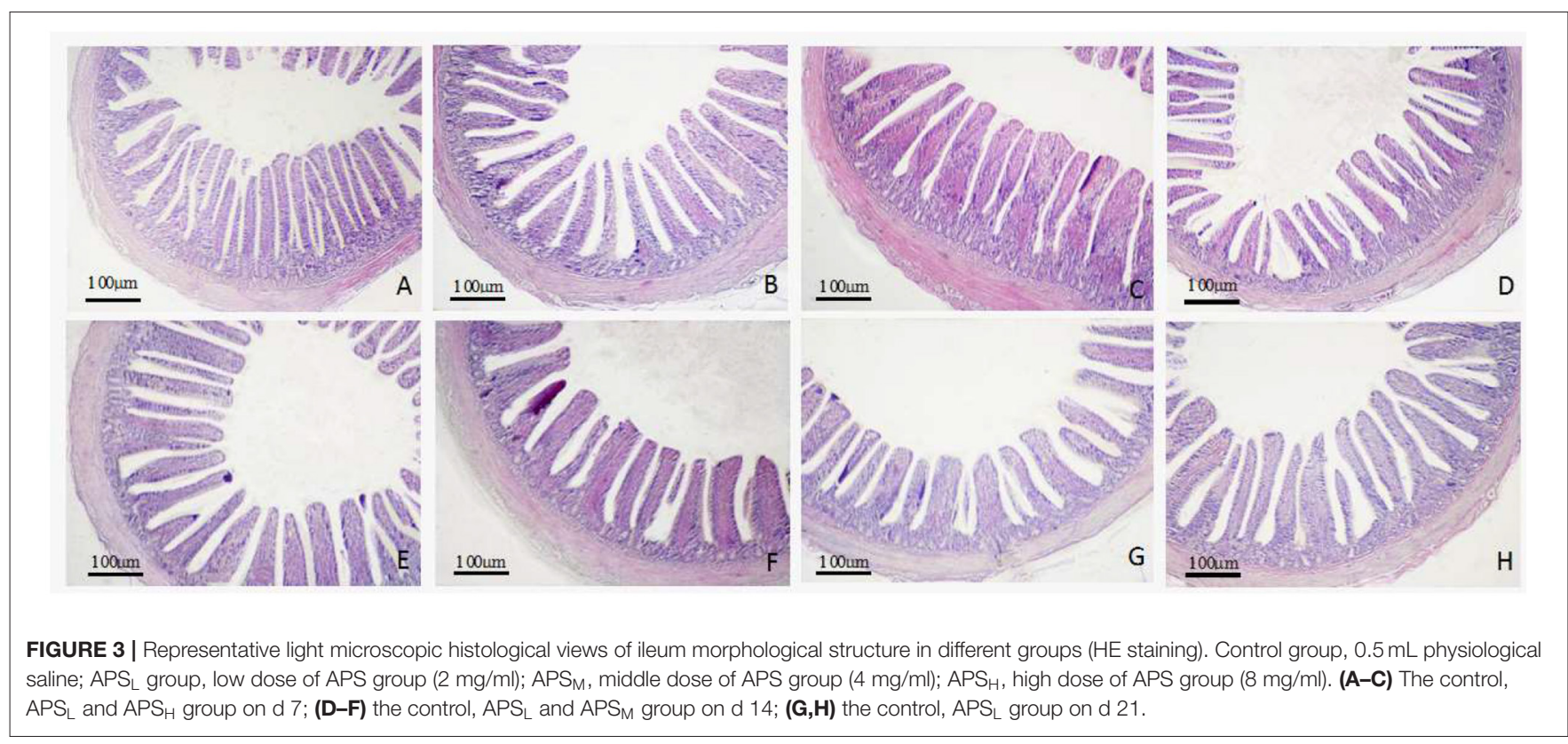

TABLE 3 | Effect of in ovo injection of APS on duodenum morphology at different ages.

\begin{tabular}{|c|c|c|c|c|c|}
\hline \multirow[t]{2}{*}{ Item } & \multicolumn{4}{|c|}{ Treatment groups* } & \multirow[t]{2}{*}{$P$-value } \\
\hline & Control & $\mathrm{APS}_{\mathrm{L}}$ & $\mathrm{APS}_{\mathrm{M}}$ & $\mathrm{APS}_{\mathrm{H}}$ & \\
\hline \multicolumn{6}{|c|}{ Villus height (VH, $\mu \mathrm{m})$} \\
\hline d 1 & $543.76 \pm 28.74$ & $537.29 \pm 20.16$ & $542.42 \pm 47.40$ & $543.31 \pm 39.35$ & 0.108 \\
\hline$d 7$ & $676.16 \pm 30.95^{c}$ & $753.16 \pm 13.97^{b}$ & $882.03 \pm 36.77^{a}$ & $738.66 \pm 27.54^{b}$ & 0.011 \\
\hline d 14 & $786.23 \pm 13.87^{b}$ & $775.16 \pm 22.45^{b}$ & $862.36 \pm 14.49^{a}$ & $778.53 \pm 17.11^{b}$ & 0.013 \\
\hline d 21 & $866.43 \pm 48.76^{c}$ & $901.30 \pm 46.8^{c}$ & $1063.76 \pm 32.88^{a}$ & $953.40 \pm 17.13^{b}$ & 0.025 \\
\hline \multicolumn{6}{|c|}{ Crypt depth (CD, $\mu \mathrm{m})$} \\
\hline d 1 & $100.33 \pm 10.99^{a}$ & $36.74 \pm 3.03^{c}$ & $55.16 \pm 6.79^{b}$ & $47.46 \pm 3.75^{\mathrm{bc}}$ & 0.004 \\
\hline$d 7$ & $122.53 \pm 21.71$ & $101.00 \pm 2.80$ & $102.4333 \pm 8.35$ & $105.73 \pm 7.28$ & 0.132 \\
\hline d 14 & $115.2 \pm 2.92^{a}$ & $95.06 \pm 17.65^{\mathrm{b}}$ & $114.3 \pm 9.77^{\mathrm{a}}$ & $114.23 \pm 4.30^{a}$ & 0.018 \\
\hline d 21 & $103.06 \pm 8.48^{\mathrm{b}}$ & $100.80 \pm 8.60^{b}$ & $144.5 \pm 13.71^{a}$ & $140.96 \pm 15.16^{a}$ & 0.027 \\
\hline \multicolumn{6}{|c|}{ VH/CD } \\
\hline d 1 & $5.43 \pm 0.33^{\mathrm{c}}$ & $14.23 \pm 0.93^{a}$ & $9.82 \pm 1.09^{b}$ & $11.52 \pm 1.34^{\mathrm{ab}}$ & 0.004 \\
\hline$d 7$ & $6.62 \pm 0.07^{b}$ & $7.46 \pm 0.33^{\mathrm{ab}}$ & $8.67 \pm 1.04^{a}$ & $7.01 \pm 0.73^{b}$ & 0.002 \\
\hline d 14 & $6.83 \pm 0.29$ & $8.34 \pm 1.55$ & $7.58 \pm 0.70$ & $6.82 \pm 0.37$ & 0.112 \\
\hline d 21 & $6.82 \pm 0.75^{b}$ & $7.40 \pm 0.80^{\mathrm{b}}$ & $8.46 \pm 0.65^{a}$ & $8.53 \pm 0.89^{a}$ & 0.015 \\
\hline
\end{tabular}

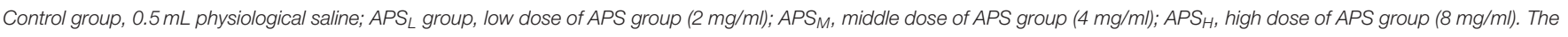
results are reported as the means \pm SEM.

${ }^{a-c}$ Means with different superscripts within the same column differ significantly $(P<0.05)$. VH/CD, the ratio of $V H$ to $C D$.

*A total of six replicates were used per treatment.

ileum from the APS groups were longer and wider than those in the control group (Figure 3).

The $\mathrm{VH}, \mathrm{CD}$, and the ratio of $\mathrm{VH} / \mathrm{CD}$ of duodenum, jejunum, and ileum are shown in Tables 3-5. In the duodenum, there were no significant differences in the $\mathrm{VH}$ among the 4 treatment groups on $\mathrm{d} 1$ ( $P>0.05$, Table 3$)$. The $\mathrm{VH}$ of duodenum significantly increased in the $\mathrm{APS}_{\mathrm{M}}$ and $\mathrm{APS}_{\mathrm{H}}$ groups on $\mathrm{d} 7$ and d 21 when compared to the control group $(P<0.05$, Table 3$)$.
However, there was no significant increase in $\mathrm{VH}, \mathrm{CD}$, and $\mathrm{VH} / \mathrm{CD}$ in the $\mathrm{APS}_{\mathrm{L}}$ group on $\mathrm{d} 14$ and $\mathrm{d} 21$ in comparison with the control group $(P>0.05$, Table 3$)$. On $\mathrm{d} 21$, the $\mathrm{VH}$ and $\mathrm{CD}$ of duodenum were highest in the $\mathrm{APS}_{\mathrm{M}}$ group among three APS groups and were significantly higher than those in the control group $(P<0.05$, Table 3$)$.

In the jejunum, no significant differences of the $\mathrm{VH}, \mathrm{CD}$, and the ratio of $\mathrm{VH} / \mathrm{CD}$ among the 4 treatment groups 
TABLE 4 | Effect of in ovo injection of APS on jejunum morphology at different ages.

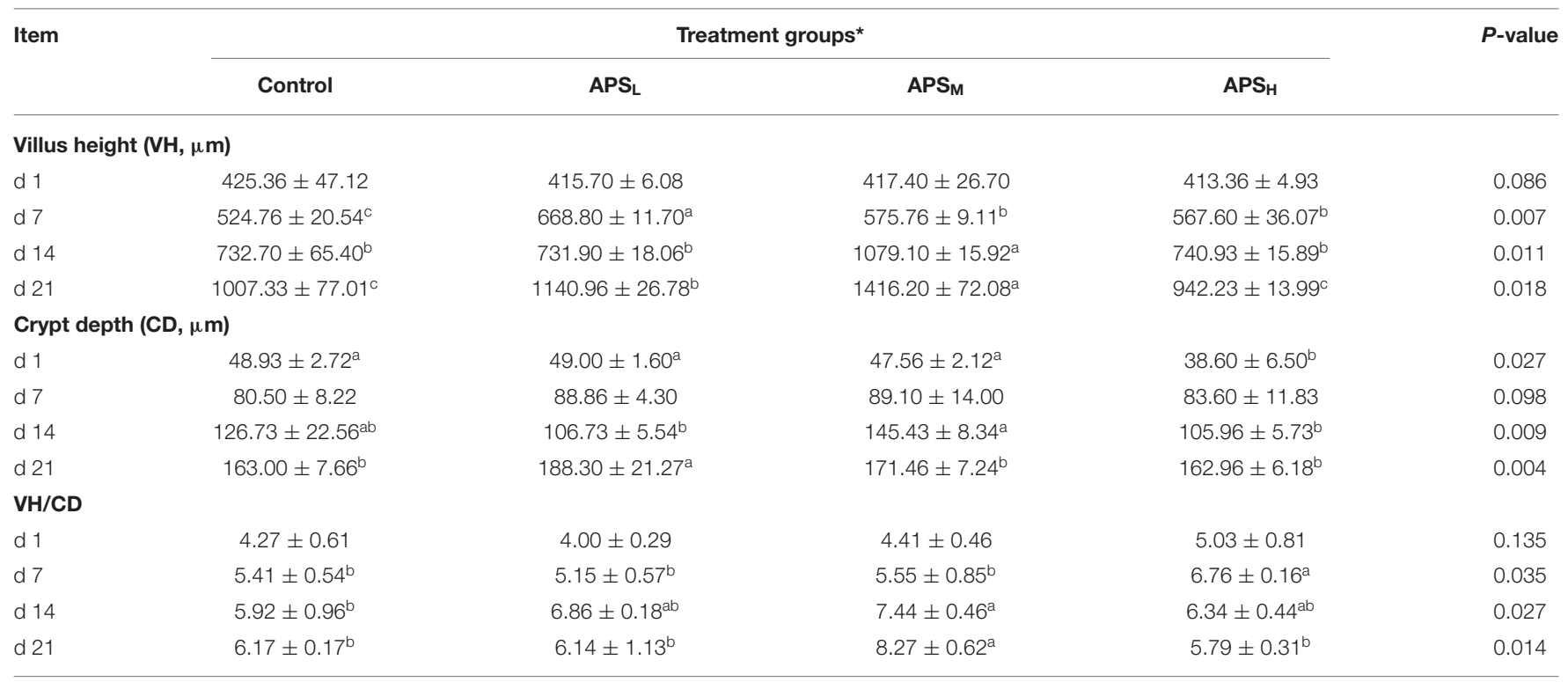

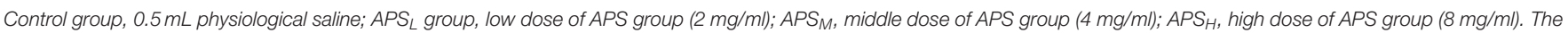
results are reported as the means $\pm S E M$.

${ }^{a-c}$ Means with different superscripts within the same column differ significantly $(P<0.05)$. VH/CD, the ratio of $V H$ to $C D$.

${ }^{*}$ A total of six replicates were used per treatment.

TABLE 5 | Effect of in ovo injection of APS on ileum morphology at different ages.

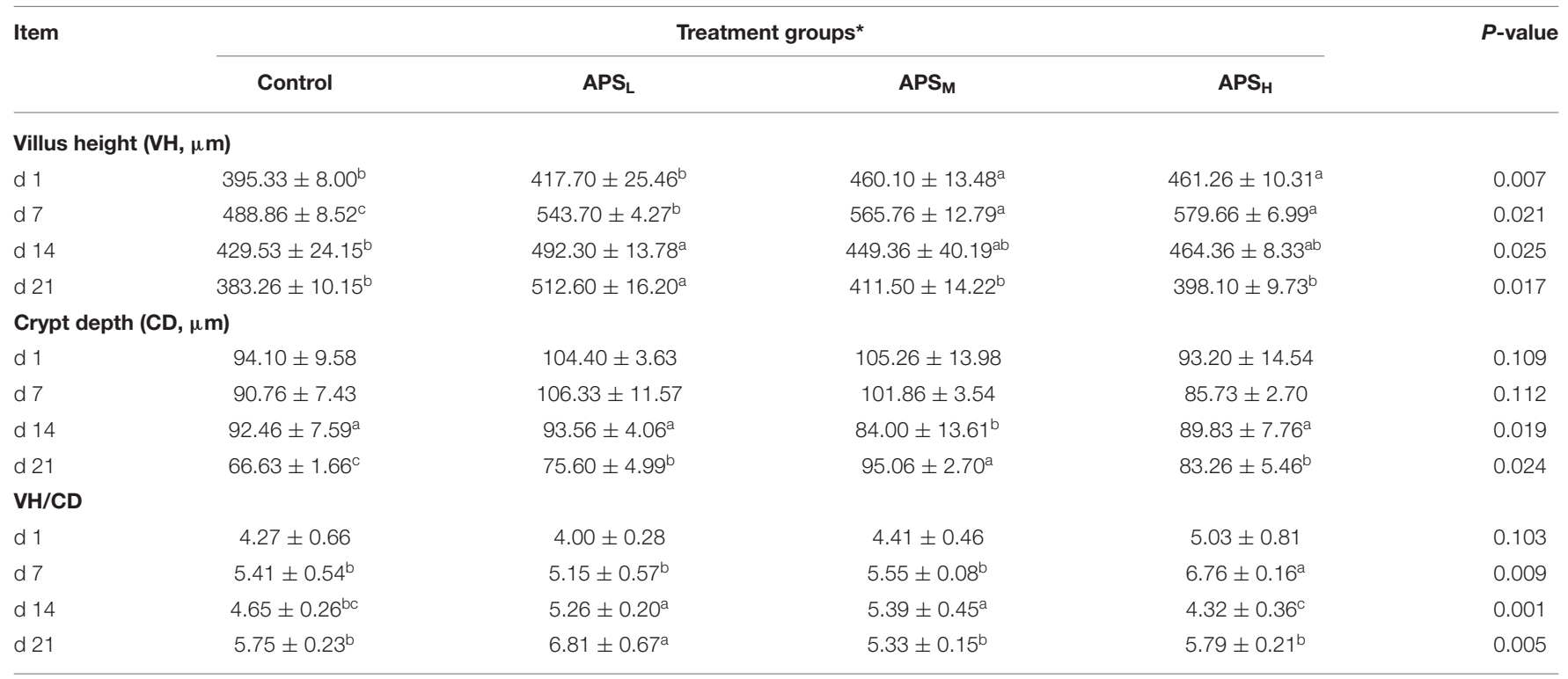

Control group, $0.5 \mathrm{~mL}$ physiological saline; APS $\mathrm{L}$ group, low dose of APS group ( $2 \mathrm{mg} / \mathrm{mll}$ ); APS , middle dose of APS group (4 mg/ml); APSH, high dose of APS group (8 mg/ml). The results are reported as the means $\pm S E M$.

${ }^{a-c}$ Means with different superscripts within the same column differ significantly $(P<0.05)$. VH/CD: the ratio of $V H$ to $C D$.

${ }^{*}$ A total of six replicates were used per treatment.

on $\mathrm{d} 1$ were observed $(P>0.05$, Table 4$)$. At most time points, the VHs of the APS groups were significantly higher than those in the control groups $(P<0.05$, Table 4), but there were no significant differences in the CDs except for the $\mathrm{APS}_{\mathrm{L}}$ group on $\mathrm{d} 21(P>0.05$, Table 4$)$. The VH/CD ratios of the $\mathrm{APS}_{\mathrm{H}}$ group on $\mathrm{d} 7$ and the $\mathrm{APS}_{\mathrm{M}}$ group on $\mathrm{d}$
21 were significantly higher than those in the control group $(P<0.05$, Table 4$)$.

In the ileum, the VHs in the $\mathrm{APS}_{\mathrm{M}}$ and $\mathrm{APS}_{\mathrm{H}}$ group on $\mathrm{d} 1$ and $\mathrm{d} 7$ were significantly higher in comparison with the control group and $\mathrm{APS}_{\mathrm{L}}$ group $(P<0.05$, Table 5$)$. The CDs of the ileum significantly increased in the three APS treatment groups when 


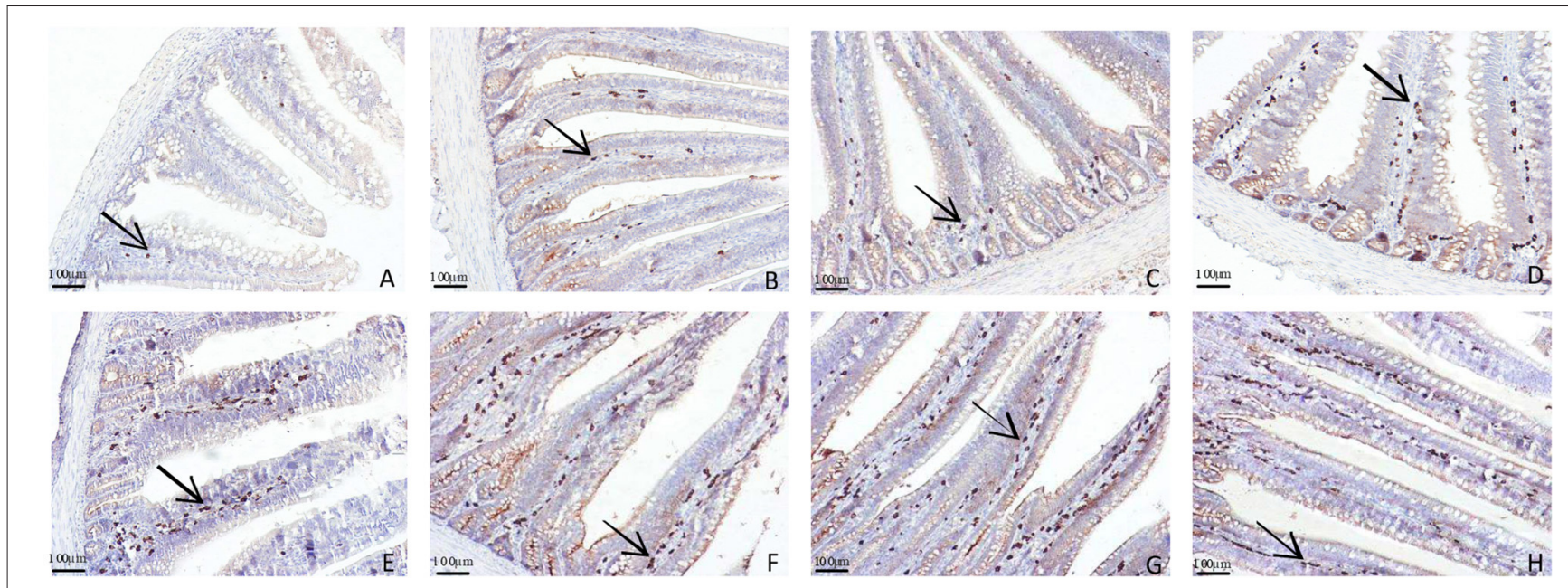

FIGURE 4 | Representative light microscopic histological views of lgA ${ }^{+}$cells in the duodenal mucosa in different groups (arrow: IgA ${ }^{+}$positive cells). Control group,

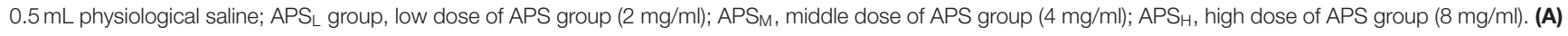
The control group on d 1; (B,C) the control and APS ${ }_{H}$ group on d 7; (D,E) the control and APS $S_{H}$ group on d 14; (F-H) the control, APS $S_{M}$ and APS group on d 21.

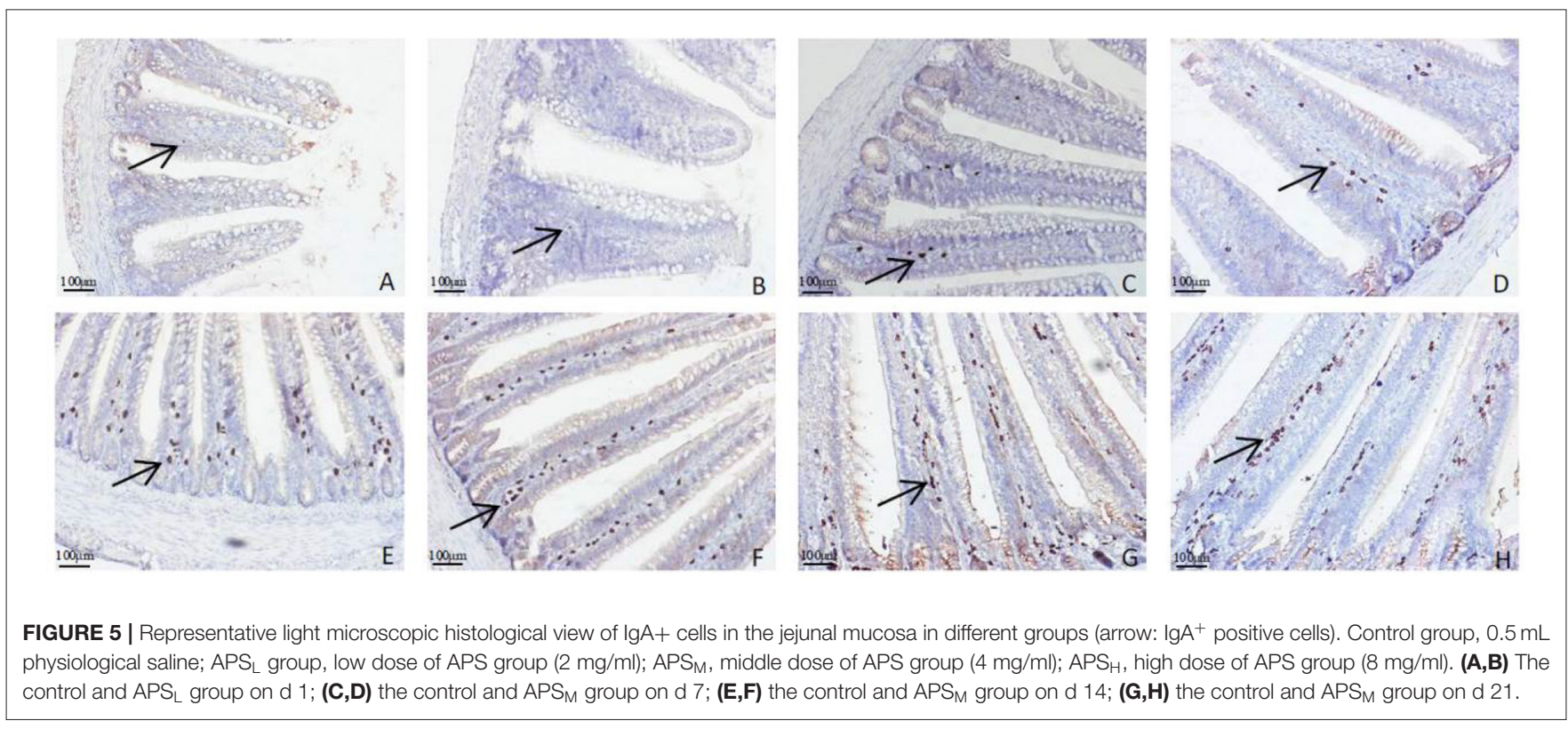

compared to the control group on d $21(P<0.05$, Table 5). On d 14 and $\mathrm{d} 21$, the ratios of $\mathrm{VH} / \mathrm{CD}$ in the $\mathrm{APS}_{\mathrm{L}}$ group were significantly higher than those in the control group $(P<0.05$, Table 5).

\section{$\lg \mathrm{A}^{+}$Cells in the Duodenal and Jejunal Mucosa}

The distributions of $\operatorname{IgA}^{+}$cells in the duodenal and jejunal mucosa are shown in Figures 4, 5. The numbers of $\operatorname{IgA}^{+}$cells in the duodenal and jejunal mucosa are shown in Figures 6A,B. On $\mathrm{d} 1, \mathrm{IgA}^{+}$cells were scattered in the lamina propria of the intestinal villi (Figure 4A), and the numbers of $\operatorname{IgA}^{+}$cells in the duodenum in all groups showed no significant differences $(P>0.05$; Figure 6A). Moreover, no obvious differences in the $\mathrm{IgA}^{+}$cell distribution were observed among the 4 treatment groups in the duodenal mucosa. On $\mathrm{d} 7$ and $\mathrm{d} 14$, more $\operatorname{Ig} \mathrm{A}^{+}$ cells were distributed in the lamina propria of the intestinal villi and around the intestinal glands in the $\mathrm{APS}_{\mathrm{H}}$ group compared to the control group (Figures 4B-E). On d 21, more IgA ${ }^{+}$cells were observed in the lower and middle parts of the lamina propria and at the bottom of the duodenal mucosa in the APS $\mathrm{M}$ and $\mathrm{APS}_{\mathrm{H}}$ groups (Figures $4 \mathrm{~F}-\mathrm{H}$ ). On d 7-21, the numbers of $\operatorname{Ig} \mathrm{A}^{+}$ 
A

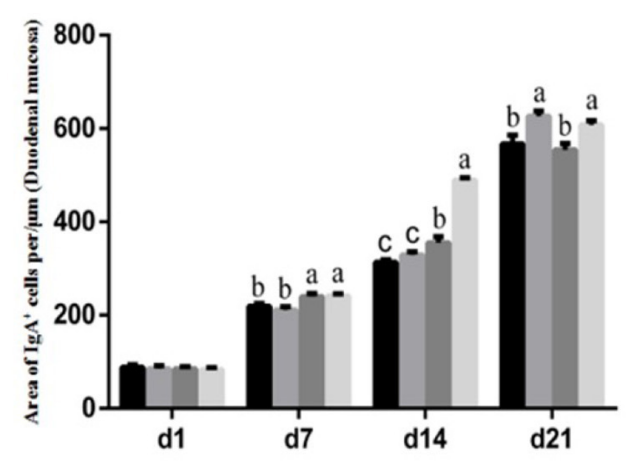

B

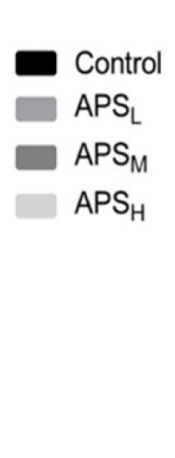

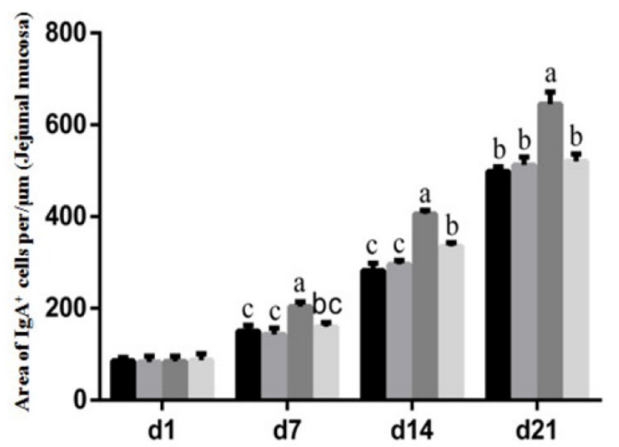

FIGURE 6 | Effects of APS on IgA ${ }^{+}$cell development in the duodenal villus (A) and the jejunal villus (B). The results are reported as the means \pm SEM. Control group, $0.5 \mathrm{~mL}$ physiological saline; APSL group, low dose of APS group (2 mg/ml); APSM, middle dose of APS group (4 mg/ml); APSH, high dose of APS group (8 mg/ml). Different letters within a column indicate significant difference among 4 treatment groups $(P<0.05)$. d, days post-hatch.

cells in the $\mathrm{APS}_{\mathrm{M}}$ and $\mathrm{APS}_{\mathrm{H}}$ groups in the duodenum were significantly higher than those in the control group $(P<0.05)$, but a significant difference was not observed between the $\mathrm{APS}_{\mathrm{L}}$ group and the control group on $\mathrm{d} 7$ and $\mathrm{d} 14$ post-hatch $(P>$ 0.05 , Figure 6A).

The distribution of $\operatorname{IgA}^{+}$cells in the jejunal mucosa was similar to the duodenal mucosa at each time point, but there were less $\operatorname{IgA}^{+}$cells in the bottom of the jejunal mucosa and around the intestinal gland in the jejunal mucosa than those in the duodenal mucosa (Figures 4D-H, 5A-H). The numbers of $\mathrm{IgA}^{+}$cells in the $\mathrm{APS}_{\mathrm{M}}$ group were significantly higher than those in the $\mathrm{APS}_{\mathrm{L}}, \mathrm{APS}_{\mathrm{H}}$, and control group on $\mathrm{d} 7$ in the jejunum $(P<$ 0.05 , Figure 6B). On $\mathrm{d} 14$ and $\mathrm{d} 21$, the $\operatorname{IgA}^{+}$cell numbers in the $\mathrm{APS}_{\mathrm{M}}$ group were significantly higher than those in the control group and the APS $\mathrm{A}_{\mathrm{L}}$ group $(P<0.05$, Figure 6B).

\section{Changes in SIgA Levels}

The effects of APS on sIgA levels in jejunum washings are shown in Figure 7. There were no significant differences in sIgA levels on $\mathrm{d} 1$ and $\mathrm{d} 14$ among the four groups $(P>0.05)$. Compared to the control group, the sIgA levels in the $\mathrm{APS}_{\mathrm{M}}$ group significantly increased on $\mathrm{d} 7$ and $\mathrm{d} 21(P<0.05)$. On $\mathrm{d} 21$, the level of sIgA in the $\mathrm{APS}_{\mathrm{H}}$ group was the highest among the four groups and was significantly higher than that in the control group and $\mathrm{APS}_{\mathrm{L}}$ group $(P<0.05)$.

\section{Expression Levels of Intestinal Immune-Related Genes}

The relative gene expression levels of IL-2, IL-6, IFN- $\gamma$, and TLR4 in the ileum were examined, and the results are shown in Figure 8. In comparison with the control group, the expression levels of IL-2 were significantly upregulated in the $\mathrm{APS}_{\mathrm{H}}$ group on $\mathrm{d} 1,7$, and $14(P<0.05$, Figure 8A). The IFN- $\gamma$ expression levels were significantly upregulated in the $\mathrm{APS}_{\mathrm{M}}$ group on d 7 and $d 14$ and significantly upregulated in the $\mathrm{APS}_{\mathrm{L}}$ group at all time points $(P<0.05$, Figure $8 \mathrm{C})$. In addition,

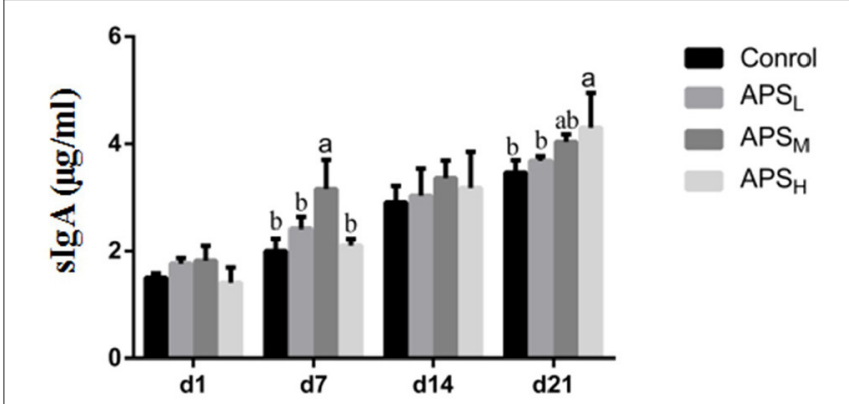

FIGURE 7 | Effect of in ovo injection of APS on slgA levels in jejunum contents. The results are reported as the means \pm SEM. Control group, $0.5 \mathrm{~mL}$ physiological saline; APSL group, low dose of APS group (2 mg/ml); APSM, middle dose of APS group ( $4 \mathrm{mg} / \mathrm{ml})$; APSH, high dose of APS group (8 $\mathrm{mg} / \mathrm{ml})$. Different letters within a column indicate significant difference among 4 treatment groups $(P<0.05)$.

there were no significant differences in the expression of IL2 on $\mathrm{d} 1$ and $\mathrm{d} 7$ among the three APS groups $(P>0.05$, Figures 8A,C). The expression levels of IL-6 were significantly higher in the $\mathrm{APS}_{\mathrm{M}}$ group and $\mathrm{APS}_{\mathrm{H}}$ group (especially in the $\mathrm{APS}_{\mathrm{H}}$ group) than those in the control group at each time point $(P<0.05$, Figure 8B). Compared to the control group, the relative expression of TLR-4 in the $\mathrm{APS}_{\mathrm{L}}$ group was higher than those in the control group on $\mathrm{d} 7$ and $\mathrm{d} 21$ $(P<0.05$, Figure 8D).

\section{DISCUSSION}

Since the administration by in ovo delivery was first reported several decades ago, various biologics, such as carbohydrates, probiotics, and synbiotics, have been injected into embryos during the incubation period for promoting the health and productivity of poultry $(1,18)$. This study aimed to 


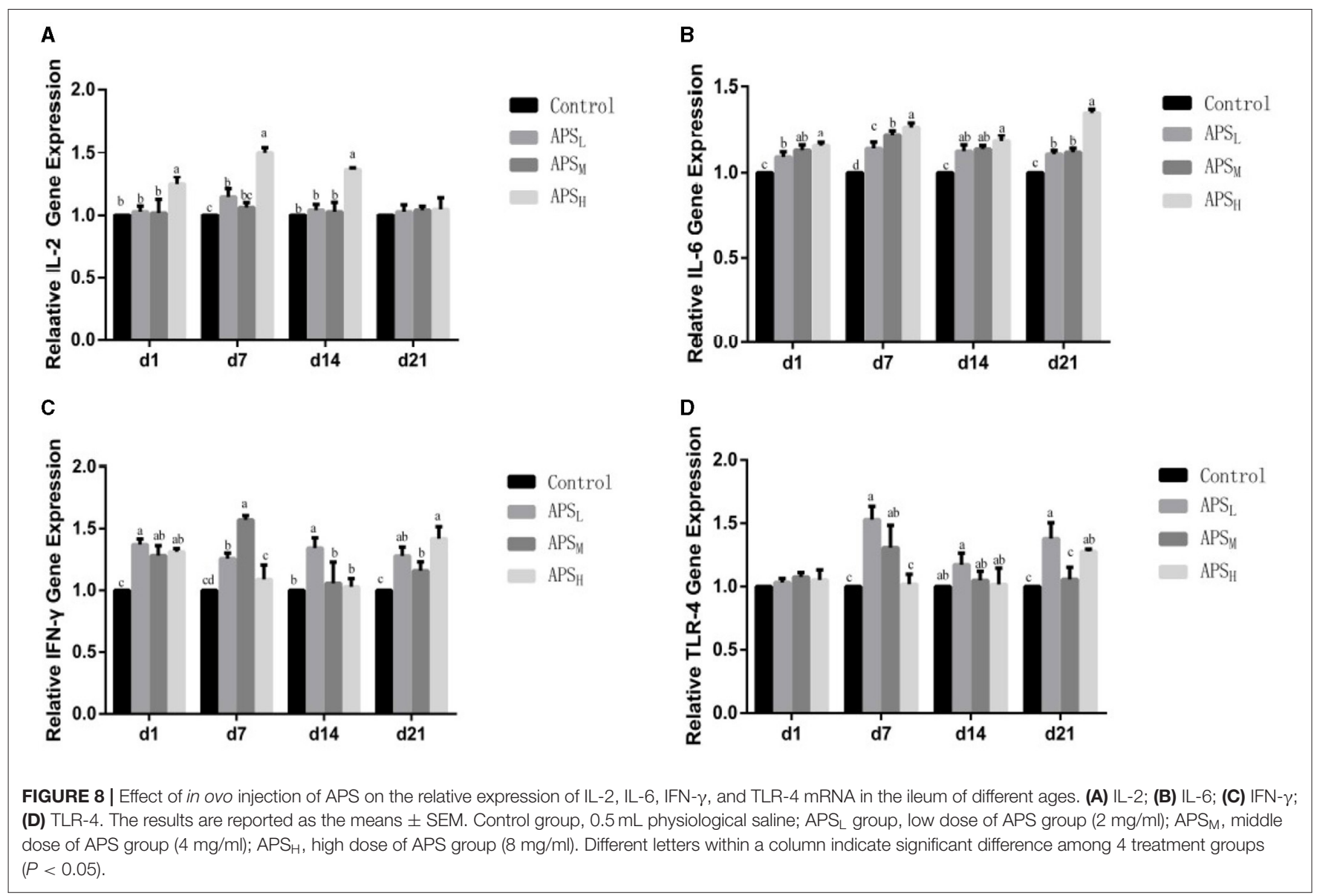

explore the effects of intra-amniotic injection of APS on growth performance, intestinal development and intestinal mucosal immunity.

In this experiment, in ovo supplementation of APS increased the BW without a negative effect of hatchability. These findings are consistent with the results reported in previous studies that both the injection of growth hormone into the albumen and the injection of lactic acid bacteria into the amnion did not affect hatchability $(19,20)$. Similarly, the injection of probiotics and drugs into the amnion did not affect hatchability or hatching weight $(21,22)$. However, other researchers have found that some carbohydrates and amino acids have been found to lead to a significantly reduced hatchability $(23,24)$. Retes et al. (25) believes that the hatchability may depend on egg size, inoculation, the volume of inoculated solution, and osmolarity. The findings of this study are suggesting that the APS can be safely administered in ovo without negatively affecting hatchability.

The small intestine is highly specialized in the hydrolysis and absorption of nutrients and constitutes the barrier between the host's external and internal environment $(26,27)$. The morphological indexes in the small intestine, such as the $\mathrm{VH}$, $\mathrm{CD}$, and $\mathrm{VH} / \mathrm{CD}$ ratio, are important indicators of its health and functional status (28). The results in this experiment showed that the intra-amniotic injection of APS improved the morphological development of the small intestine on $\mathrm{d} 7-\mathrm{d} 21$, as indicated by an increase in $\mathrm{VH}$ and the ratio of VH/CD. The promoting effects of APS in the small intestine varied with the APS concentration, time point evaluated after hatch and the intestinal segment. However, it was not feasible to compare the data obtained from this experiment with the data from the literature, as most of those studies have been focused on the impact of APS by dietary inclusion that was not administered in ovo (29). In other studies, the $\mathrm{VH}$ and $\mathrm{CD}$ of the intestine were increased due to the intra-amniotic injection of nutrients $(30,31)$. Increased VH and CD enhance absorption and digestive capabilities (32). It was speculated that the early feeding of APS in the present study could increase the yolk-reserve utilization to enhance the small intestine growth and development in the late stage of hatching. Meanwhile, these surplus nutrients would continue to be utilized by the hatchling chicks during the fasting period.

Intestinal mucosal immunity is the first barrier against pathogen invasion in chickens, with more than $70 \%$ of immune cells ( $\mathrm{T}$ cells, $\mathrm{B}$ cells, macrophages) located in the intestinal mucosa (33). The intestinal lamina propria contains abundant B lymphocytes, especially $\operatorname{IgA}^{+}$cells. These $\operatorname{IgA}^{+}$ cells form an important mucosal protective layer on the 
surface of the intestinal mucosal and play an important role in protecting the intestinal tract from pathogenic infection. The sIgA produced by activated B cells is the most important factor in the mucosal adaptive immune system, forming a protective layer on the intestinal mucosal surface, and requires cytokines with immunomodulatory activity to guard against the incursion of harmful pathogens (34). The results of this study showed that APS delivered in ovo did not influence the number of $\operatorname{IgA}^{+}$cells and the sIgA content on $\mathrm{d} 1$ posthatch. However, APS could increase the number of $\mathrm{IgA}^{+}$ cells in the intestinal mucosa and the sIgA content in the intestinal washings from $\mathrm{d} 7$ to $\mathrm{d} 21$. The ideal time period for injection was late-term avian embryo with delivery to the amniotic fluid. The embryo consumes the amniotic fluid and its contents are exposed to the intestines and the enteric cells that comprise them. Therefore, APS administered to this region will be consumed along with the amniotic fluid and presented to enteric tissues, and further enhanced intestinal mucosal immunity.

This study demonstrates that APS administration could increase the relative mRNA expression of IL-2, IL-6, IFN- $\gamma$, and TLR-4. As an important member of the Toll-like receptor family, TLR-4 can recognize microbial-associated molecular patterns of expression of infectious agents and plays an important role in the detection of pathogens. Increased TLR-4 is associated with an enhanced gastroepithelial barrier, which provides defense against pathogen invasion and infection (35). IL-6 is a key ingredient in cytokine network, not only participates in the inflammatory response, but also promotes the production of immune globulin. IL-2 and IFN- $\gamma$ are important cytokines that play a fundamental role in stimulating the proliferation of $\mathrm{B}$ lymphocytes and $\mathrm{T}$ lymphocytes by inhibiting the production of pro-inflammatory modulators (36). The results in this experiment showed that the three doses of APS could have different effects on the gene expression of IL-2, IL-6, IFN- $\gamma$, and TLR-4. In ovo injection with $\mathrm{APS}_{\mathrm{H}}$ had the most obvious positive effect on the gene expression of IL-2 and IL-6, and the gene expression of TLR4 was most significantly increased at d 14 and $\mathrm{d} 21$ in the $\mathrm{APS}_{\mathrm{L}}$ group. However, the three doses of APS had different effects on the increase in IFN- $\gamma$ gene expression at different time points. Previous studies have shown that in ovo feeding is helpful for the early immune response. Humphrey and Rudrappa (37) reported that in ovo injection of fructose or ribose could promote cell-mediated immunity genes by enhancing the expression of IL-2, IL-12, and IFN- $\gamma$. Similar results were also found with the in ovo injection of lysine, threonine, methionine, and cystine (38). In addition to carbohydrates and amino acids, El-Senousey et al. (39) have shown that vitamin C could enhance the immune response by significantly decreasing the mRNA level of IL- 6 , IL- $1 \beta$, and TNF- $\alpha$. These findings suggested that in ovo feeding could confer a moderate effect of cellular immunity by regulating the production of related cytokines and cellular receptors.

\section{CONCLUSIONS}

This study confirmed that the in ovo administration of APS does not impact hatchability and may increase the BW at $14 \mathrm{~d}$ and 21 $\mathrm{d}$ post-hatch. In addition, at most time points, in ovo injection of APS at 1 and $2 \mathrm{mg} /$ egg doses could promote the intestinal development and increase the $\operatorname{IgA}^{+}$cells and sIgA content in the intestinal mucosa. Furthermore, in ovo injection of APS could alter the expression of several immune-related genes within the ileum. This study reveals that in ovo administration of APS could enhance the intestinal development and mucosal immunity in the early stages post-hatch, which provides timely and effective protection for chickens.

At most time points, the villus height $(\mathrm{VH})$ was increased $(P<0.05)$ and the crypt depth $(\mathrm{CD})$ was decreased $(P<0.05)$ in the small intestine of the broilers, with higher $\mathrm{VH} / \mathrm{CD}$ ratios in the APSL and APSM groups compared with the control group.

\section{DATA AVAILABILITY STATEMENT}

All data generated or analyzed during this study are available from the corresponding author on reasonable request.

\section{ETHICS STATEMENT}

The animal study was reviewed and approved by the Jilin Agriculture University Institutional Animal Care and Use Committee (JLAU08201409).

\section{AUTHOR CONTRIBUTIONS}

Y-nZ and XM designed the study. A-qJ and A-yD assisted with data analysis. S-bY, D-hZ, Y-jQ, W-mL, and PS performed animal tests, interpreted the results, and wrote the manuscript draft. All authors have read and approved the manuscript.

\section{FUNDING}

This work was financially supported by the 13th FiveYear Science and Technology Plan Item of Jilin Provincial Education Department (Grant Nos. JJKH20200355KJ and JJKH20201293JY), Jilin province science and technology development plan (Grant No. 20190201148JC), and the Doctoral Research Start-up Fund of Jilin Medical University (Grant Nos. JYBS2021014LK and JYBS2021016LK). The funding agencies had no role in the design of the study and data collection, analysis, and interpretation of data or in writing the manuscript.

\section{ACKNOWLEDGMENTS}

The authors thank the Animal Development and Immune Regulation Lab of Jilin Agricultural University for technical support. 


\section{REFERENCES}

1. Ghanaatparast-Rashti M, Mottaghitalab M, Ahmadi H. In ovo feeding of nutrients and its impact on post-hatching water and feed deprivation up to $48 \mathrm{hr}$, energy status and jejunal morphology of chicks using response surface models. J Anim Physiol Anim Nutr. (2018) 102:E806-17. doi: $10.1111 /$ jpn. 12838

2. Foye OT, Uni Z, Ferket PR. Effect of in ovo feeding egg white protein, beta-hydroxy-beta-methylbutyrate, and carbohydrates on glycogen status and neonatal growth of turkeys. Poult Sci. (2006) 85:1185-92. doi: $10.1093 / \mathrm{ps} / 85.7 .1185$

3. Nasir Z, Peebles ED. Symposium: avian embryo nutrition and incubation. Poult Sci. (2018) 97:2994-95. doi: 10.3382/ps/pey137

4. Miller CC, Cook ME. Evidence against the induction of immunological tolerance by feeding antigens to chickens. Poult sci. (1994) 73:106-12. doi: $10.3382 /$ ps. 0730106

5. Brandtzaeg P. Mucosal immunity: induction, dissemination, and effector functions. Scand J Immunol. (2009) 70:505-15. doi: 10.1111/j.1365-3083.2009.02319.x

6. Muir WI, Bryden WL, Husband AJ. Immunity, vaccination and the avian intestinal tract. Dev Comp Immunol. (2000) 24:325-42. doi: 10.1016/s0145-305x(99)00081-6

7. Bar Shira E, Sklan D, Friedman A. Impaired immune responses in broiler hatchling hindgut following delayed access to feed. Vet Immunol Immunopathol. (2005) 105:33-45. doi: 10.1016/j.vetimm.2004.12.011

8. Kadam MM, Barekatain MR, Bhanja SK, Iji PA. Prospects of in ovo feeding and nutrient supplementation for poultry: the science and commercial applications-a review. J Sci Food Agric. (2013) 93:3654-61. doi: $10.1002 /$ jsfa.6301

9. Pruszynska-Oszmalek E, Kolodziejski PA, Stadnicka K, Sassek M, Chalupka $\mathrm{D}$, Kuston $\mathrm{B}$, et al. In ovo injection of prebiotics and synbiotics affects the digestive potency of the pancreas in growing chickens. Poult Sci. (2015) 94:1909-16. doi: 10.3382/ps/pev162

10. Triplett MD, Zhai W, Peebles ED, McDaniel CD, Kiess AS. Investigating commercial in ovo technology as a strategy for introducing probiotic bacteria to broiler embryos. Poult sci. (2018) 97:658-66. doi: 10.3382/ps/ pex317

11. Zheng Y, Ren W, Zhang L, Zhang Y, Liu D, Liu Y. A review of the pharmacological action of astragalus polysaccharide. Front pharmacol. (2020) 11:349-59. doi: 10.3389/fphar.2020.00349

12. Kallon S, Li XR, Ji J, Chen CY, Xi QY, Chang S, et al. Astragalus polysaccharide enhances immunity and inhibits H9N2 avian influenza virus in vitro and in vivo. Anim Sci Biotechnol. (2013) 4:22. doi: 10.1186/2049-1891-4-22

13. Xie JH, Jin ML, Morris GA, Zha XQ, Chen HQ, Yi Y, et al. Advances on bioactive polysaccharides from medicinal plants. Crit Rev Food Sci Nutr. (2016) 56:S60-84. doi: 10.1080/10408398.2015.10 69255

14. Shan CL, Sun BD, Dalloul RA, Zhai ZC, Sun P, Li MH, et al. Effect of the oral administration of astragalus polysaccharides on jejunum mucosal immunity in chickens vaccinated against Newcastle disease. Microb Pathog. (2019) 135:103621. doi: 10.1016/j.micpath.2019.1 03621

15. Dalloul RA, Lillehoj HS, Tamim NM, Shellem TA, Doerr JA. Induction of local protective immunity to Eimeria acervulina by a Lactobacillusbased probiotic. Comp Immunol Microbiol Infect Dis. (2005) 28:351-61. doi: 10.1016/j.cimid.2005.09.001

16. Yang YR, She RP, Zheng SM, Jiang YB. Effect of probiotics on intestinal mucosal immunity and ultrastructure of cecal tonsils of chickens. Arch Anim Nutr. (2005) 59:237-46. doi: 10.1080/17450390500216928

17. Giansanti F, Giardi MF, Botti D. Avian cytokines-an overview. Curr Pharm Des. (2006) 12:3083-99. doi: 10.2174/138161206777947542

18. Zhai W, Rowe DE, Peebles ED. Effects of commercial in ovo injection of carbohydrates on broiler embryogenesis. Poult Sci. (2011) 90:1295-301. doi: 10.3382/ps.2010-01130

19. Kocamis H, Yeni YN, Kirkpatrick-Keller DC, Killefer J. Postnatal growth of broilers in response to in ovo administration of chicken growth hormone. Poult Sci. (1999) 78:1219-26. doi: 10.1093/ps/78.8.1219
20. Teague KD, Graham LE, Dunn JR, Cheng HH, Anthony N, Latorre JD, et al. In ovo evaluation of FloraMax (R)-B11 on Marek's disease HVT vaccine protective efficacy, hatchability, microbiota composition, morphometric analysis, and Salmonella enteritidis infection in broiler chickens. Poult Sci. (2017) 96:2074-82. doi: 10.3382/ps/pew494

21. McGruder BM, Zhai W, Keralapurath MM, Bennett LW, Gerard PD, Peebles ED. Effects of in ovo injection of electrolyte solutions on the pre- and posthatch physiological characteristics of broilers. Poult Sci. (2011) 90:105866. doi: 10.3382/ps.2010-00893

22. Pender CM, Kim S, Potter TD, Ritzi MM, Young M, Dalloul RA. In ovo supplementation of probiotics and its effects on performance and immunerelated gene expression in broiler chicks. Poult Sci. (2017) 96:1052-62. doi: $10.3382 / \mathrm{ps} / \mathrm{pew} 381$

23. Dong XY, Wang YM, Song HH, Zou XT. Effects of in ovo injection of carbohydrate solution on small intestine development in domestic pigeons (Columba livia). J Anim Sci. (2013) 91:3742-49. doi: 10.2527/jas.2013-6400

24. Ohta Y, Tsushima N, Koide K, Kidd MT, Ishibashi T. Effect of amino acid injection in broiler breeder eggs on embryonic growth and hatchability of chicks. Poult Sci. (1999) 78:1493-8. doi: 10.1093/ps/78. 11.1493

25. Retes PL, Clemente AHS, Neves DG, Esposito M, Makiyama L, Alvarenga RR, et al. In ovo feeding of carbohydrates for broilers a systematic review. J Anim Physiol Anim Nutr. (2018) 102:361-9. doi: 10.1111/jpn.12807

26. Sobolewska A, Elminowska-Wenda G, Bogucka J, Dankowiakowska A, Kulakowska A, Szczerba A, et al. The influence of in ovo injection with the prebiotic DiNovo $($ on the development of histomorphological parameters of the duodenum, body mass and productivity in large-scale poultry production conditions. J Anim Sci Biotechno. (2017) 8:45. doi: 10.1186/s40104-017-0176-2

27. Sobolewska A, Elminowska-Wenda G, Bogucka J, Szpinda M, Walasik K, Bednarczyk M, et al. Myogenesis-possibilities of its stimulation in chickens. Folia Biol-Krakow. (2011) 59:85-90. doi: 10.3409/fb59_3-4.85-90

28. Calik A, Ergun A. Effect of lactulose supplementation on growth performance, intestinal histomorphology, cecal microbial population, and short-chain fatty acid composition of broiler chickens. Poult Sci. (2015) 94:2173-82. doi: $10.3382 / \mathrm{ps} / \mathrm{pev} 182$

29. Yan ZF, Liu NX, Mao XX, Li Y, Li CT. Activation effects of polysaccharides of Flammulina velutipes mycorrhizae on the T lymphocyte immune function. $J$ Immunol Res. (2014) 2014:285421. doi: 10.1155/2014/285421

30. Sklan D, Ashkenazi R, Braun A, Devorin A, Tabori K. Fatty acids, calcium soaps of fatty acids, and cottonseeds fed to high yielding cows. $J$ dairy sci. (1992) 75:2463-72. doi: 10.3168/jds.S0022-0302(92)78008-4

31. Tako E, Ferket PR, Uni Z. Effects of in ovo feeding of carbohydrates and betahydroxy-beta-methylbutyrate on the development of chicken intestine. Poult sci. (2004) 83:2023-28. doi: 10.1093/ps/83.12.2023

32. Drazbo A, Ognik K, Zaworska A, Ferenc K, Jankowski J. The effect of raw and fermented rapeseed cake on the metabolic parameters, immune status, and intestinal morphology of turkeys. Poult Sci. (2018) 97:3910-20. doi: $10.3382 / \mathrm{ps} /$ pey 250

33. Muller CA, Autenrieth IB, Peschel A. Innate defenses of the intestinal epithelial barrier. Cell Mol Life Sci. (2005) 62:1297-307. doi: 10.1007/s00018-005-5034-2

34. Rothkotter HJ, Hriesik C, Barman NN, Pabst R. B and also T lymphocytes migrate via gut lymph to all lymphoid organs and the gut wall, but only $\operatorname{Ig} \mathrm{A}^{+}$cells accumulate in the lamina propria of the intestinal mucosa. Eur J immunol. (1999) 29:327-33. doi: 10.1002/(sici)15214141(199901)29:01 <327::Aid-immu327>3.3.Co;2-b

35. Loures FV, Pina A, Felonato M, Araujo EF, Leite KRM, Calich VLG. Toll-like receptor 4 signaling leads to severe fungal infection associated with enhanced proinflammatory immunity and impaired expansion of regulatory $\mathrm{T}$ Cells. Infect Immun. (2010) 78:1078-88. doi: 10.1128/iai.01198-09

36. Lee KW, Lee SH, Lillehoj HS, Li GX, Jang SI, Babu US, et al. Effects of direct-fed microbials on growth performance, gut morphometry, and immune characteristics in broiler chickens. Poult Sci. (2010) 89:203-16. doi: 10.3382/ps.2009-00418

37. Humphrey BD, Rudrappa SG. Increased glucose availability activates chicken thymocyte metabolism and survival. J Nutr. (2008) 138:1153-7. doi: $10.1093 /$ jn/138.6.1153 
38. Bhanja SK, Hotowy A, Mehra M, Sawosz E, Pineda L, Vadalasetty KP, et al. In ovo administration of silver nanoparticles and/or amino acids influence metabolism and immune gene expression in chicken embryos. Int J Mol Sci. (2015) 16:9484-503. doi: 10.3390/ijms16059484

39. El-Senousey HK, Chen B, Wang JY, Atta AM, Mohamed FR, Nie QH. Effects of dietary vitamin $\mathrm{C}$, vitamin $\mathrm{E}$, and alpha-lipoic acid supplementation on the antioxidant defense system and immune-related gene expression in broilers exposed to oxidative stress by dexamethasone. Poult Sci. (2018) 97:30-8. doi: $10.3382 / \mathrm{ps} / \mathrm{pex} 298$

Conflict of Interest: The authors declare that the research was conducted in the absence of any commercial or financial relationships that could be construed as a potential conflict of interest.
Publisher's Note: All claims expressed in this article are solely those of the authors and do not necessarily represent those of their affiliated organizations, or those of the publisher, the editors and the reviewers. Any product that may be evaluated in this article, or claim that may be made by its manufacturer, is not guaranteed or endorsed by the publisher.

Copyright (C) 2021 Yang, Qin, Ma, Luan, Sun, Ju, Duan, Zhang and Zhao. This is an open-access article distributed under the terms of the Creative Commons Attribution License (CC BY). The use, distribution or reproduction in other forums is permitted, provided the original author(s) and the copyright owner(s) are credited and that the original publication in this journal is cited, in accordance with accepted academic practice. No use, distribution or reproduction is permitted which does not comply with these terms. 